\title{
O PROGRAMA OPERADOR ECONÔMICO AUTORIZADO (OEA BRASILEIRO) E AS OPERAÇÕES DE IMPORTAÇÃO E EXPORTAÇÃO
}

\author{
Reginaldo da Silva SOUZA ${ }^{1}$ \\ Cleiton Paiva Rodrigues LUCIANO² \\ Daniel Reis dos SANTOS ${ }^{3}$ \\ Breno Henrique PRADO SILVA ${ }^{4}$ \\ Sheldon William SILVA \\ Sergio Ricardo MAGALHÃES ${ }^{6}$
}

\begin{abstract}
${ }^{1}$ Mestre em Administração pela Faculdade Pedro Leopoldo - FPL-MG. reginaldo_vga @ hotmail.com
${ }^{2}$ Bacharel em Administração pelo Centro Universitário do Sul de Minas - UNIS-MG. cepi@unis.edu.br

${ }^{3}$ Bacharel em Administração pela Faculdade Cenecista de Varginha - FACECA-MG. reginaldo_vga@ @otmail.com

${ }^{4}$ Bacharel em Administração pelo Centro Universitário do Sul de Minas - UNIS-MG. cepi@unis.edu.br

${ }^{5}$ Mestre em Administração pela Faculdade Pedro Leopoldo - FPL-MG. sheldonwilliamsilva@gmail.com

${ }^{6}$ Doutor em Engenharia Biomédica pelo IP\&D - SJC. sergio.magalhaes@ unincor.edu.br
\end{abstract}

Recebido em: 06/07/2016 - Aprovado em: 19/03/2017 - Disponibilizado em: 01/07/2017

\begin{abstract}
RESUMO
O programa OEA - Operador Econômico Autorizado é tema mais atual e um dos principais programas criados pelo governo brasileiro para o comércio exterior nos últimos tempos. Baseado no Programa C-TPAT criado pela Aduana Americana, voltado à segurança física da carga, o OEA brasileiro consiste na certificação dos intervenientes na cadeia logística, exportadores, importadores, transportadores, agentes de cargas, depositários de mercadoria sobre controle aduaneiro, operadores portuários ou aeroportuários e despachantes aduaneiros, que apresentam confiabilidade nas suas operações logísticas e obrigações aduaneiras. O objetivo do presente artigo é verificar quais os possíveis impactos na logística internacional para os agentes desta cadeia logística ao se certificarem no programa OEA - Operador Econômico Autorizado, analisando as peculiaridades referentes ao processo de certificação do programa OEA e os benefícios logísticos que tal benefício pode proporcionar aos operadores certificados. Por meio de uma pesquisa documental e um estudo de caso de uma empresa habilitada no Programa OEA foi possível identificar: os principais requisitos para a habilitação no OEA; os benefícios logísticos da utilização do programa e; entender as motivações das empresas para buscarem a habilitação no programa.
\end{abstract}

Palavras-chave: Comércio Exterior. Importações e Exportações. OEA.

\begin{abstract}
The OEA program - Authorized Economic Operator is more current theme and one of the main programs created by the Brazilian government for foreign trade in recent times. Based on C-TPAT created by Aduana American Program, focused on physical security charge, the Brazilian OEA is the certification of the players in the logistics chain, exporters, importers, shippers, cargo agents, commodity custodians of customs control, port operators or airport and customs brokers, which provide reliability in their logistics and customs compliance operations. The purpose of this article is to verify what the possible impacts on international logistics for the agents of the supply chain to make sure the OEA program - Authorized Economic Operator, analyzing the peculiarities related to the certification process of the OAS program and logistical benefits such benefit can provide certified operators. Through desk research and a case study of a qualified company in the OEA program was identified: the main requirements for enabling the OEA; the logistical benefits of using the program and; understand the motivations of companies to seek to enable the program.
\end{abstract}

Keywords: Foreign Trade. Imports and Exports. OEA. 


\section{INTRODUÇÃO}

Os mercados estão cada vez mais competitivos e as empresas precisam alinhar as suas estratégias de produção às estratégias competitivas globais, dessa forma, a logística internacional tem papel fundamental no desenvolvimento da competitividade nas operações de comércio internacional (ROCHA, 2013; SOUZA, 2012). A logística internacional é um elemento fundamental para que os fluxos dos diversos tipos de recursos aconteçam da forma mais eficiente possível, o que se torna muito desafiador quando se considera que existe uma busca laboriosa pela redução de tempo e custo.

Nesse contexto, as empresas brasileiras, ao realizarem as operações de importação e exportação, buscam agilidade, competitividade em custos, um atendimento diferenciado e uma logística que atendam às suas mais diversas necessidades (SOUZA; LARA, 2015).

O programa OEA é tema mais atual e um dos principais programas criados pelo governo brasileiro para o comércio exterior nos últimos tempos. O OEA brasileiro foi desenvolvido com base no Programa C-TPAT criado pela Aduana Americana, voltado à segurança física da carga. De acordo com o último relatório oficial emitido pela Organização Mundial das Aduanas (OMA), cinquenta e seis países possuem programas OEA em franca operação. A Receita Federal do Brasil, em levantamento extraoficial, afirma, no entanto, que há setenta e sete países operando por meio de Programas de OEA, incluindo-se o Brasil e outros trinta e quatro países com programas em desenvolvimento (RECEITA FEDERAL, 2016).

O OEA brasileiro consiste na certificação dos intervenientes na cadeia logística, exportadores, importadores, transportadores, agentes de cargas, depositários de mercadoria sobre controle aduaneiro, operadores portuários ou aeroportuários e despachantes aduaneiros, que apresentam confiabilidade nas suas operações logísticas e obrigações aduaneiras. A certificação do programa não é obrigatória, ou seja, os operadores certificados pelo OEA irão usufruir das vantagens logísticas, aduaneiras e dos benefícios de futuros acordos de reconhecimento mútuo e os operados não certificados não usufruirão de tais benefícios (PROCOMEX, 2016).

O objetivo do presente artigo é identificar os possíveis impactos na logística internacional para os agentes desta cadeia ao se certificarem no programa OEA - Operador Econômico Autorizado, analisando as peculiaridades referentes ao processo de certificação do programa OEA e os benefícios logísticos que tal benefício pode proporcionar aos operadores certificados. Dessa forma, pretende-se responder à seguinte questão: Quais os desafios e as oportunidades para os importadores e exportadores ao se certificarem no programa OEA - Operador Econômico Autorizado? 
Por meio de uma pesquisa documental e um estudo de caso de uma empresa habilitada no Programa OEA foi possível identificar: os principais requisitos para a habilitação no OEA; os benefícios logísticos da utilização do programa e; entender as motivações das empresas para buscarem a habilitação no programa.

\section{REFERENCIAL TEÓRICO}

\subsection{O COMÉRCIO E A LOGÍSTICA INTERNACIONAL}

A concorrência global, a evolução das economias emergentes, a preocupação com a utilização sustentável dos recursos não renováveis, o avanço das tecnologias, a redução das barreiras alfandegárias, são fatores que contribuem para a evolução do comércio internacional nas suas mais variadas formas (SOUZA, 2015).

O processo de busca da competividade internacional e o aumento da participação dos produtos importados no mercado interno acontecem cada vez mais, com a contribuição da efetividade da internacionalização das atividades das empresas, notadamente as grandes corporações. Neste sentido, elas devem buscar a redução de custos pela escala comercial, novos mercados consumidores, a diversificação das suas atividades, uma melhor utilização de recursos naturais, emprego de mão de obra cada vez mais especializada, melhoria da infraestrutura, entre outros tantos fatores (SOUZA, 2015).
O comércio exterior brasileiro evoluiu significativamente nas últimas duas décadas, com destaque para os anos 2000 com avanço das exportações brasileiras que cresceram, aceleradamente, até o ano de 2009. Os últimos cinco anos, no entanto, foram marcados por oscilações elevadas nos volumes de importações e exportações, com destaque para o ano de 2015, que fechou com uma queda brusca nas importações.

Apesar do crescimento que o comércio exterior brasileiro vem apresentando nas últimas décadas, a infraestrutura logística do país não tem demonstrado uma evolução no mesmo ritmo que os importadores e exportadores necessitam, gerando assim custos adicionais aos produtores, que sem opção de escoamento da produção, acabam se submetendo ao sistema dispendioso (MACHADO et al., 2013).

De acordo com Christopher (2013, p. 19), "estamos entrando na era da "concorrência da cadeia de suprimentos",. Ainda segundo o autor (2013), a diferença mais evidente entre o modelo tradicional de concorrência e o modelo contemporâneo é que uma organização já não pode mais agir como uma entidade isolada e independente em concorrência com outras organizações "isoladas". Em vez disso, devem criar sistemas de entregas de valores, mais sensíveis às demandas mercadológicas constantemente mutáveis, mais consistentes e confiáveis na entrega de tal valor, exigindo 
dessa forma, que toda a cadeia de suprimentos esteja focada na obtenção desses objetivos.

De forma sucinta, pode se definir cadeia de logística internacional como um conjunto de etapas pela qual uma mercadoria percorre, desde o momento em que sai de sua origem (exportador - vendedor) até a sua chegada ao destino final (importador comprador). Nesse caminho atuam diversos intervenientes, tais como: transportadores, agente de cargas, terminais de despacho, despachantes aduaneiros, entre outros (RECEITA FEDERAL, 2015).

De acordo com Souza (2011), o êxito na gestão de uma empresa que atua no mercado internacional é resultado de uma intensa integração funcional entre vendas, compras, qualidade, produção, suprimentos, transportes e comercio exterior. Portando, para uma boa gestão logística, no comércio internacional, é fundamental que toda organização esteja atuando de forma horizontal, ágil e rápida para responder às constantes modificações do mercado. Todavia, vale ressaltar que acelerar os fluxos da cadeia de suprimentos é algo complexo, sendo preponderante administrá-los e conhece-los para ser ter a máxima eficiência em toda a cadeia.

O Brasil encontra-se ainda em fase de transição no que diz respeito à logística integrada. Ainda que seja evidente que em alguns setores já se note a preocupação com a aplicação dos conceitos de gerenciamento da logística, de modo que algumas empresas estão começando a reestruturar suas atividades utilizando-se dessa nova perspectiva, no contexto geral ainda há um longo caminho a ser percorrido para chegar ao desenvolvimento da logística na indústria nacional e dos transportes (ROCHA, 2013).

Dentre os setores que se desenvolveram na logística integrada no Brasil, destaca-se o setor de produção de minérios, principalmente o de ferro destinado à exportação. Também o setor agrícola merece reconhecimento, considerando que o Brasil tem conseguido implementar soluções logísticas para driblar os problemas de falta de infraestrutura, da falta de armazéns especializados e de baixa eficiência nos portos. Em ambos os casos, soluções que envolvam despachos aduaneiros rápidos e desburocratizados e regimes aduaneiros que facilitem o fluxo comercial são de suma importância (ROCHA, 2013).

Além da ineficiência dos modais transportes, a burocracia no Brasil figura como um dos principais entraves para o eficaz funcionamento dos trâmites administrativos aduaneiros e consequentemente reduz a eficiência da logística internacional, causando uma inversão de parâmetros nos fatores de competitividades, sobretudo no preço dos produtos brasileiros nos mercados consumidores. De acordo com Lopes e Gama (2013), os custos logísticos no Brasil podem ser reduzidos em média $50 \%$ do que se verifica atualmente, se forem implementados mecanismos e políticas equivalentes aos 
adotados por outros países mais competitivos no mercado internacional, de modo que sejam otimizados os principais gargalos logísticos do país.

Diante deste contexto, o Brasil está implementando o programa OEA que tem como principal objetivo, por meio de certificação dos agentes envolvidos na cadeia de logística internacional, a redução da burocracia e agilidade nos trâmites do processo aduaneiro, a seguir serão apresentadas às principais características do programa OEA.

\subsection{O PROGRAMA BRASILEIRO DE OEA}

\section{E SEUS REQUISITOS}

O OEA consiste na certificação dos intervenientes na cadeia logística, exportadores, importadores, transportadores, agentes de cargas, depositários de mercadoria sobre controle aduaneiro, operadores portuários ou aeroportuários e despachantes aduaneiros, que apresentam confiabilidade nas suas operações logísticas e obrigações aduaneiras (PROCOMEX, 2016).

A certificação do programa não é obrigatória, ou seja, os operadores certificados pelo OEA irão usufruir das vantagens logísticas, aduaneiras e dos benefícios de futuros acordos de reconhecimento mútuo e os operados não certificados não usufruirão de tais benefícios (PROCOMEX, 2016).

Para os operadores se certificarem no OEA, é necessário que possuam as condições e requisitos determinados pela Instrução Normativa da Receita Federal do Brasil $\mathrm{n}^{\circ}$ $1.598 / 15$. É preciso que os operadores atendam os requisitos de admissibilidade, no qual o operador torna-se apto a participar do processo de certificação no OEA, os critérios de elegibilidade que indica a confiabilidade do operador e os critérios específicos por modalidade e interveniente (RECEITA FEDERAL, 2016).

O programa OEA do Brasil está estruturado em modalidades: OEA-S Operador Econômico Autorizado Segurança, destinado às empresas exportadoras, agentes de carga, despachantes aduaneiros, operadores portuários e aeroportuários, depositários, transportadores; OEA-C - Operador Econômico Autorizado Conformidade, destinado às empresas importadoras, sendo que dentro dessa modalidade existem dois níveis: OEA-C nível 1 e OEA-C nível 2, a seguir serão apresentados os requisitos e benefícios de cada modalidade; OEA-P Operador Econômico Autorizado Pleno, destinado a empresas importadoras e exportadoras e; OEA-I - Operador Econômico Integrado, visa à integração de outros órgãos governamentais além da Receita Federal, como ANVISA e VIGIAGRO, essa modalidade ainda está em fase de implementação, com previsão de lançamento em dezembro de 2016 e não será foco deste estudo (RECEITA FEDERAL, 2015). A tabela 01 demonstra os requisitos e 
critérios básicos para as certificações dos modelos OEA.

Os requisitos de Admissibilidade e os Critérios de Elegibilidade são aplicados em todas as fases do Programa Brasileiro de OAE (OEA-Segurança, OEA-Conformidade e OEA-Pleno), caso o operador esteja certificado em alguma modalidade OEA e busque uma nova certificação, serão analisados apenas os critérios específicos da nova certificação (ASSOSIAÇÃO BRASILEIRA DE ESTUDOS ADUANEIROS, 2016).

Para a modalidade de certificação do OEA-Segurança e OEA-Pleno os critérios de segurança estão relacionados ao controle de unidade de carga; controle de acesso físico; treinamento em segurança; conscientização de ameaças; procedimentos de segurança e; segurança física das instalações (IN RFB $n^{\circ}$ $1.598 / 15)$.

Para a certificação da modalidade OEA-Conformidade Níveis 1 e 2 e OEAPleno, os critérios de conformidade relacionam-se aos processos que garantem o cumprimento das obrigações aduaneiras e tributárias, dispostos em onze temas: sistema de contabilidade e registro fiscal; política de verificação documental e controle de estoque; descrição completa das mercadorias; capacitação e desenvolvimento; classificação fiscal; operações indiretas, operações cambiais; apuração da base de cálculos dos tributos e do preço das exportações; cumprimento das normas relativas a regimes especiais e aplicados em áreas especiais, suspensões, isenções e demais benefícios fiscais no âmbito aduaneiro; regra de origem; rastreabilidade das mercadorias (IN RFB $\mathrm{n}^{\circ}$ 1.598/15). Após os operadores serem aprovados em todos os requisitos, será emitido o Certificado OEA em reconhecimento à parceria entre a empresa e aduana.

Para melhor competitividade no mercado internacional, os operadores econômicos precisam analisar, de forma sistêmica e holística, todo processo logístico e aduaneiro. No Brasil, há um elevado gasto com tributos, logística e muita burocracia nos trâmites aduaneiros, o que limita a competitividade das empresas no comércio internacional.

A gestão dos fluxos logísticos é fundamental para as empresas minimizarem custos em suas atividades e maximizarem resultados em seus processos, proporcionando mais competitividade no mercado internacional (SOUZA, 2011).

Com o Programa Brasileiro OEA projeto que visa à facilitação, padronização, simplificação, modernização e harmonização no comércio exterior - os trâmites aduaneiros serão simplificados trazendo benefícios para as empresas que operam na importação e exportação (ANEFAC, 2016).

Conforme IN RFB $\mathrm{n}^{\circ} 1.598 / 15$ os benefícios são usufruídos de caráter geral e por modalidade. Os benefícios de caráter geral, mencionado no art. $9^{\circ}$, são concedidos a 
todas as modalidades de certificação (OEA-S, OEA-C e OEA-P). Já o art. $10^{\circ}$ traz os benefícios, especificamente, oferecidos aos operadores certificados na modalidade OEASegurança e OEA-Pleno. $O$ art. $11^{\circ}$ traz os benefícios específicos para os operadores certificados na modalidade OEAConformidade (Níveis 1 e 2) e para o OEAPleno. E por último o art. $12^{\circ}$ traz os benefícios específicos para os operadores certificados na modalidade OEAConformidade Nível 2 e para o OEA-Pleno (RECEITA FEDERAL, 2016).

Os benefícios do Programa Brasileiro OEA, podem ser utilizados tanto nas operações de importação quantos nas exportações e por modalidade de certificação, conforme sintetizado na tabela 01 .

Tabela 01 - Benefícios das Modalidades de Certificações

\begin{tabular}{|c|c|c|c|c|}
\hline Beneficins & $\$$ & $C 1$ & C2 & Pleno \\
\hline Putccitat ws shoder RBB & $x$ & $X$ & $x$ & $X$ \\
\hline 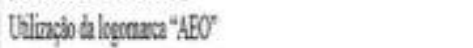 & $x$ & $X$ & $x$ & X \\
\hline Resodecotion a REB & $x$ & $\mathrm{X}$ & $x$ & $X$ \\
\hline 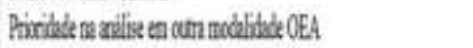 & $x$ & $X$ & $X$ & $X$ \\
\hline 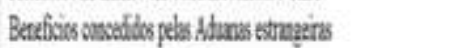 & $x$ & $X$ & $x$ & $x$ \\
\hline Patripusion to Finn Cossultio & $\mathrm{X}$ & $X$ & X & $X$ \\
\hline 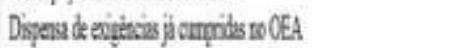 & $x$ & $X$ & $x$ & $x$ \\
\hline 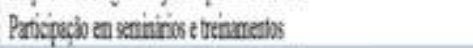 & $\mathrm{X}$ & X & $x$ & X \\
\hline 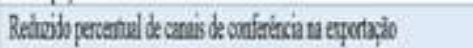 & $X$ & & & X \\
\hline 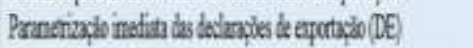 & $x$ & & & $x$ \\
\hline 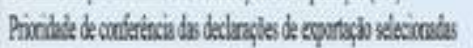 & $x$ & & & $x$ \\
\hline 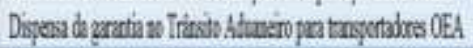 & $x$ & & & X \\
\hline 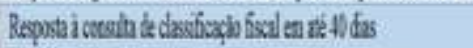 & & $\mathrm{X}$ & $\mathrm{x}$ & $x$ \\
\hline 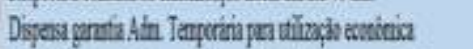 & & $X$ & X & X \\
\hline 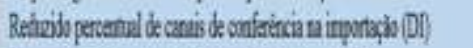 & & & $\mathrm{X}$ & X \\
\hline 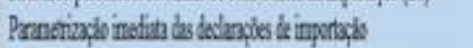 & & & \ & $x$ \\
\hline 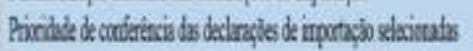 & & & $x$ & $X$ \\
\hline 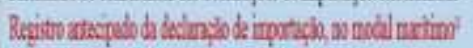 & & & $x$ & $X$ \\
\hline 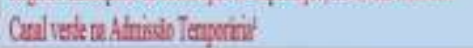 & & & $x$ & $x$ \\
\hline
\end{tabular}

Fonte: Receita Federal (2016).
O governo espera que até 2019, 50\% (cinquenta por cento) de todas as declarações de importação e exportação registradas no Brasil sejam feitas por empresas certificadas no programa OEA (RECEITA FEDERAL, 2015).

O Programa Brasileiro OEA baseia-se na desburocratização do processo administrativo aduaneiro e na redução dos custos logísticos nos processos de exportação e importação para os operadores certificados. Todos os benefícios demonstrados na tabela 02 refletem na redução do tempo de liberação das cargas submetidas ao despacho aduaneiro de importação ou de exportação e na facilitação das operações aduaneiras brasileiras e estrangeiras (RECEITA FEDERAL, 2016).

Devido à praticidade dos trâmites aduaneiros, os custos logísticos alfandegários serão reduzidos, e o tempo de envio e recebimento da mercadoria será mais ágil. Os importadores e exportadores participantes do Programa OEA, além de todos os benefícios informados na tabela 02 contarão com uma redução de custo em armazenamento (nas zonas alfandegárias), agilidade na movimentação de carga dentro do recinto alfandegado, gestão de estoque (Just in time), ganho de agilidade e eficiência de toda operação logística, redução do custo de inventário e melhores resultados para a empresa.

Por meio das medidas de facilitação e agilização dos procedimentos aduaneiros, os 
benefícios concedidos aos operadores certificados como OEA, serão usufruídos em qualquer alfândega. Conforme Receita Federal (2016):

[...] um dos principais benefícios do Programa OEA aos OEA-Segurança, a redução do percentual de seleção para canais de conferência na exportação, percebeu-se, desde a entrada em operação deste benefício em junho de 2015, uma redução drástica ao percentual médio de $1,5 \%$ de canais de seleção. Isso significa que $98,5 \%$ das declarações de exportação dos OEA-S foram direcionadas ao canal VERDE. Este percentual representa uma de redução de $82,7 \%$ na média do percentual de seleção para canais de conferência dos operadores não OEA, na exportação.

Uma logística eficiente é peça fundamental para galgar melhores resultados. Por isso, o programa OEA veio para melhorar a competitividade dos agentes econômicos que operam no comércio exterior, fornecendo estruturas e políticas para descomplicar o desembaraço aduaneiro.

\subsection{REGIME ADUANEIRO LINHA AZUL X} OEA

Para agilizar os trâmites aduaneiros e reduzir os percalços oriundos do excesso de burocracia diversos mecanismos foram desenvolvidos no Brasil, dentre os quais se destaca como o mais recente e mais abrangente, o Programa Brasileiro de Operador Econômico Autorizado (OEA). O programa OEA difere dos tradicionais regimes aduaneiros especiais, no sentido de que estes existem para propiciar alternativas operacionais eficientes aos importadores e exportadores e para atender situações atípicas com finalidades específicas ou proporcionar benefícios tributários, enquanto o OEA, embora proporcione benefícios semelhantes, é mais abrangente e consiste em uma certificação concedida pelas aduanas a importadores, exportadores e demais atores da cadeia logística internacional, que confere o status de empresa segura e confiável em suas operações de comércio exterior.

O Regime especial de Linha Azul também conhecido como Despacho Aduaneiro Expresso teve a sua primeira versão em 1998, inicialmente não era um programa de âmbito nacional, funcionando apenas no Aeroporto Internacional de Viracopos em Campinas. Segundo Souza et al. (2015) o regime aduaneiro de Linha Azul foi um programa de âmbito nacional, pensado como uma forma de reduzir o excesso de burocracia no processo administrativo aduaneiro e reduzir custos logísticos e seus benefícios se estendiam apenas importadores e exportadores.

As empresas já certificadas no Linha Azul tiveram a oportunidade realizar a transição para o OEA-C Nível 1, com manutenção dos benefícios utilizados como empresa habilitada à Linha Azul. Porém, as empresas que não requisitaram esta transição deixaram de usufruir de tais benefícios automaticamente a partir de março de 2016 (RECEITA FEDERAL, 2016).

Em caráter de comparação no que tange os benefícios dos dois programas, o 
OEA sobressai ao Linha Azul com um conjunto muito mais amplo de benefícios, além de se estender para diversos atores da cadeia logística, enquanto o Linha Azul era restrito apenas aos importadores e exportadores de alguns segmentos de mercado.

De acordo com Souza et al. (2015), os principais benefícios do Linha Azul estão relacionados à parametrização das operações no Sistema Integrado de Comércio Exterior SISCOMEX ocorrendo preferencialmente para canal verde - desembaraço automático e à conferência aduaneira prioritária para cargas selecionadas. No OEA estes benefícios também se aplicam, mas de forma mais abrangente, comtemplando ainda outros benefícios tais como: registro antecipado da Declaração de Importação, utilização da logo marca "OEA" conferindo o título de empresa segura para operar no comércio exterior, além de benefícios concedidos pelas Aduanas Estrangeiras.

\section{ASPECTOS METODOLÓGICOS}

$\mathrm{O}$ artigo do ponto de vista de seus objetivos baseia-se em uma pesquisa exploratória e os meios utilizados foram a pesquisa bibliográfica e um estudo de caso.

A pesquisa exploratória segundo Silva e Menezes (2001, p. 21) "visa proporcionar maior familiaridade com o problema com vistas a torna-lo explícito ou a construir hipóteses [...] Assume, em geral, as formas de Pesquisas Bibliográficas e Estudos de Caso”.
De acordo com Gil (2002) a pesquisa bibliográfica é embasada a partir de material já publicado, constituído principalmente por artigos periódicos, livros e também através de material de internet. $\mathrm{O}$ estudo bibliográfico foi baseado nos seguintes temas: o comércio exterior brasileiro, importações, exportações e regime aduaneiros especiais.

A pesquisa documental, apesar de ser semelhante à pesquisa bibliográfica, faz o uso de materiais que ainda não foram analisados, podendo ser reelaborados conforme os objetivos do estudo (GIL, 2002).

Ainda segundo Gil (2002), o estudo de caso consiste no estudo profundo e exaustivo de um ou poucos objetos, de maneira que permita seu amplo e detalhado conhecimento, tarefa praticamente impossível mediante outros delineamentos já considerados.

O estudo de caso foi desenvolvido por meio de uma entrevista em profundidade com um executivo da área de importação de uma empresa habilitada no programa OEA, instalada no estado de Minas Gerais, para melhor entendimento destas operações, analisando as características do programa brasileiro de OEA e as vantagens logísticas proporcionadas pela sua utilização. A entrevista foi realizada no mês de maio de 2016, sendo a escolha da empresa baseada no critério de acessibilidade.

\section{ANÁLISE E DISCUSSÃO DOS DADOS}

Diante do estudo realizado, buscou-se identificar e entender o funcionamento da 
certificação OEA, assim como, os benefícios atribuídos ao programa. Para melhor entendimento a análise foi divida em duas etapas, na primeira foram analisadas as estatísticas fornecidas pela Receita Federal, já na segunda etapa serão apresentados os principais resultados da entrevista realizada com uma empresa habilitada no programa.

O Programa Brasileiro OEA já conta com setenta e seis empresas certificadas, que apresentam uma logística de baixo grau de risco e que poderão contribuir com a agilidade no fluxo das operações de importações e exportações brasileiras

(RECEITA FEDERAL, 2016).

A figura 01 sintetiza a quantidade e categorias dos operadores econômicos e as modalidades de certificações.

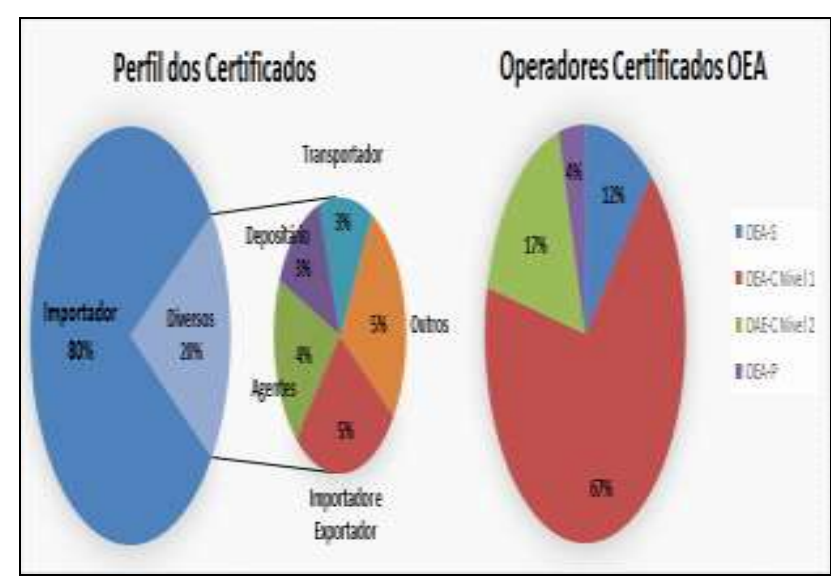

Figura 01 - Estatística de Certificações por Quantidade, Categoria e Modalidade.

Do total das setenta e seis empresas certificadas, sessenta e seis são Importadores e Exportadores, ficando somente dez empresas dentre os demais intervenientes: transportadores, agentes de cargas, depositários de mercadoria sobre controle aduaneiro, operadores portuários ou aeroportuários e por enquanto não há nenhum despachante aduaneiro certificado.

Considerando os setenta e seis operadores certificados, $67 \%$ foram certificados como OEA-C Nível 1, 17\% foram certificados como OEA-C Nível 2, $12 \%$ foram certificados como OEA-S e apenas $4 \%$ foram certificados como OAE-P.

Uma das principais vantagens do regime OEA para os importadores e exportadores é a agilidade no desembaraço aduaneiro. A figura 02 apresenta a incidência dos canais de parametrização no período de março de 2015 até maio de 2016 nas operações de exportação. É possível visualizar na evolução do gráfico, que a as empresas certificadas no OEA passaram a apresentar um índice de seleção para conferência (canais laranja e vermelho) significativamente menor que as empresas não habilitadas no programa.

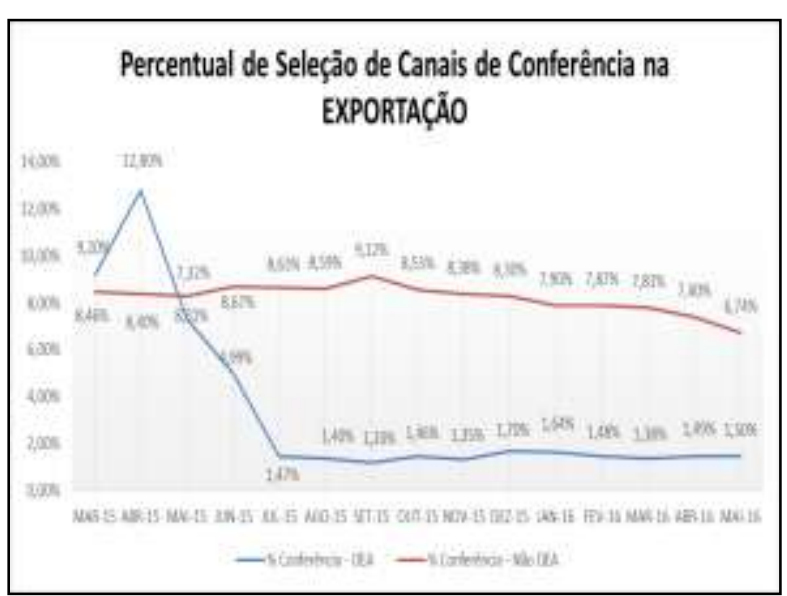

Figura 02 - Percentual de Seleção de Canais de Conferência na Exportação.

A figura 03 apresenta a redução do percentual de seleção aos canais de 
conferência na importação, o início de sua operação foi em dezembro de 2015, com o OEA-Conformidade Nível 2. Analisando-se os dados da Receita Federal (2016) é possível que concluir que a média de seleção das declarações para canais de conferência entre os operadores não-OEA é de $9,51 \%$, enquanto a média de parametrização entre as empresas habilitadas é de $2,75 \%$ de incidência em canais diferentes de verde. Isso significa que $97,25 \%$ das declarações de importação dos OEA-C são direcionadas ao canal verde, com liberação automática e a Receita Federal pretende elevar esse percentual para $99 \%$ das operações para as empresas habilitadas no programa.

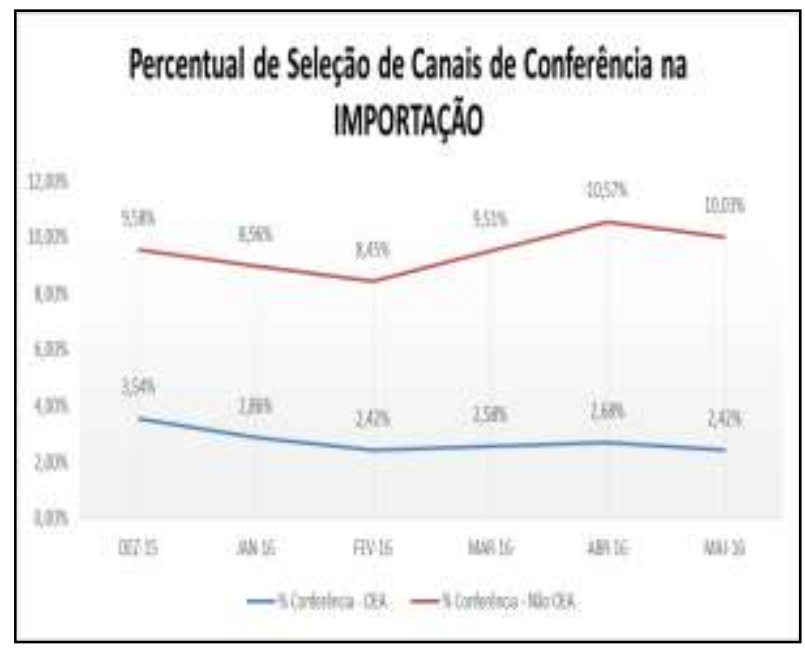

Figura 03 - Percentual de Seleção de Canais de Conferência na Importação.

A principal implicação desses dados é a agilidade no desembaraço dos processos de importação e exportação. Consequentemente, essas operações se tornam mais baratas, uma vez que as mercadorias ficam por menos tempo armazenadas, sendo possível a redução de pagamento de despesas para os terminais portuários, sobre-estadias de caminhões, demurrages entre outras taxas da operação. É possível constatar, portanto, que o programa OEA contribui para o aumento da competitividade das operações do comércio exterior brasileiro.

Se de um lado o programa beneficia as empresas participantes, do outro lado o governo também ganha com a operação. Pois, com o processo de habilitação no OEA, o estado passa arrecadar mais, com o aumento do giro de operações das empresas, além disso, o nível de confiança nas empresas habilitadas é elevado, evitando a sonegação de impostos e até mesmo ações ilícitas nas operações de comércio exterior, além de ser um convite para empresas que possuem débitos com o fisco e operações irregulares a se regularizarem no curto prazo para obterem a certificação. Outro aspecto importante para o governo trata-se da melhoria da sua imagem no cenário do comércio internacional. $\mathrm{O}$ Brasil ainda é considerado um país muito fechado para o comércio internacional. A redução das barreiras alfandegárias é uma busca incansável da Organização Mundial do Comércio (OMC) e de outros organismos internacionais. O programa OEA brasileiro, que foi criado a partir de programas similares em países desenvolvidos tenderá a melhorar a reputação brasileira e sem dúvidas, a partir da sua consolidação, será tido como um grande avanço da legislação aduaneira brasileira.

A segunda etapa da pesquisa foi destinada à análise do estudo de caso. A 
empresa analisada tem sua unidade fabril instalada no estado de Minas Gerais e possui escritórios administrativos nos estados de Minas Gerais, São Paulo, Rio de Janeiro e Distrito Federal. Com mais de trinta e cinco anos de atuação no mercado brasileiro, a empresa apresentou forte crescimento nos últimos anos. Atualmente, a companhia realiza operações de importação, exportação e regimes aduaneiros especiais como: Entreposto Aduaneiro; Admissão Temporária e Exportação Temporária. Conforme já explorado anteriormente, o OEA é uma certificação concedida pelas Aduanas a importadores, exportadores, agentes de cargas, terminais, e outras empresas que atuam na cadeia logística que apresentam segurança em suas operações. A Empresa entrevistada obteve sua certificação no ano de 2016 por meio da migração da habilitação do Despacho Aduaneiro Expresso - Linha Azul para a certificação OEA- Conformidade Nível 1.

Ao ser questionado sobre as principais dificuldades para conseguir a habilitação e se manter no programa, a empresa analisada apontou que até o presente momento não ocorreu nenhuma dificuldade, devido a sua antiga habilitação no regime aduaneiro especial Linha Azul. Ainda de acordo com o entrevistado, o programa exige que a empresa mantenha os procedimentos e instruções de trabalho claras e atualizadas, além de fazer o controle periódico da segurança da cadeia logística. O gestor entrevistado apontou ainda que a empresa trabalha de forma comprometida com as regras aduaneiras, tributárias e de segurança da cadeia logística com o objetivo de obter o OEA Pleno em breve.

Uma observação faz-se necessária sobre esse aspecto. Como a empresa já possuía o benefício do regime aduaneiro especial Linha Azul é natural que a obtenção do OEA - Conformidade Nível 1, tenha sido um processo, relativamente, fácil. Entretanto, pelos requisitos para habilitação no OEA apresentados no referencial teórico, pode ser que empresas de menor porte, que estejam tentando a habilitação não tenham a mesma facilidade, tendo em vista o nível de exigência da Receita Federal para conceder à habilitação no programa.

Considerando as vantagens do programa OEA propostas pela Receita Federal, foi questionado ao entrevistado quais benefícios identificados durante o processo de importação após a certificação. Pela percepção da empresa, os principais impactos foram na incidência do canal verde, segundo o gestor entrevistado, atualmente $99 \%$ de suas cargas são parametrizadas no canal verde e liberadas automaticamente. $\mathrm{O}$ gestor apresentou também, que houve um estreitamento da relação com a Receita Federal que passou a atender a empresa via telefone e e-mail, agilizando o processo de consultas e resolução de problemas referentes ao processo de desembaraço. Tornaram-se perceptivos também, benefícios relacionados 
ao marketing, tais como publicidade no site da Receita Federal e a utilização da logomarca OEA.

Outros benefícios identificados pela empresa estão relacionados à prioridade na análise do pedido de certificação de operador que já tenha sido certificado em outra modalidade ou nível do Programa Brasileiro de OEA, e também, a dispensa de apresentação de garantia para o importador OEA na concessão do regime de admissão temporária para utilização econômica.

Todos os benefícios apresentados pela empresa estão de acordo com o material publicado pela Receita Federal e que foram explorados no referencial teórico, mais especificamente na Tabela 02, na qual se apresentou os benefícios e requisitos das modalidades de certificações. Há de se observar que alguns benefícios elencados pela Receita Federal não foram apontados pela empresa analisada, tais como: benefícios de acordos de Reconhecimento Mútuo (ARM) que a Receita Federal venha a assinar com as aduanas de outros países, e, respostas à consulta de classificação fiscal de mercadorias em até 40 dias. Talvez, a ausência desses benefícios, seja em função da empresa ainda não ter realizado nenhuma consulta pública à Receita Federal e não ter se beneficiado, ainda, de nenhum acordo firmado com a aduana de outros países.

Apesar de reconhecida evolução nas operações, o gestor apresentou na entrevista que ainda existem alguns desafios na operação de importação, especialmente, no que diz respeito às barreiras não tarifárias impostas pelo governo federal brasileiro. A principal barreira apontada pelo gestor foi à dificuldade de obtenção do licenciamento de importação dos órgãos anuentes, que realizam intervenções no controle aduaneiro, tais como: ANP (Agência Nacional do Petróleo, Gás Natural e Biocombustíveis), ANVISA (Agência Nacional de Vigilância Sanitária), IBAMA (Instituto Brasileiro do Meio Ambiente e dos Recursos Naturais Renováveis), INMETRO (Instituto Nacional de Metrologia, Qualidade e Tecnologia) e DFPC (Diretoria de Fiscalização de Produtos Controlados do Exército Brasileiro).

Mais especificamente no contexto logístico, o gestor entrevistado foi questionado sobre os principais impactos da certificação no OEA na gestão logística da empresa, apontando que houve uma redução do custo de inventário (Turnover), sendo possível a aplicação do modelo just in time, também, para as operações de compras internacionais.

Outro aspecto apontado pelo gestor foi que as operações de importação ganharam agilidade nos recintos alfandegados e consequentemente isso possibilitou a redução dos custos com armazenamento nas zonas alfandegárias, além do ganho de agilidade e eficiência de toda operação logística.

Por fim, o gestor apresentou que programa brasileiro de OEA é muito relevante para promover o comércio exterior do país, 
"trata-se de uma realidade que chega para tornar o Brasil mais competitivo em relação a outros países”.

\section{CONCLUSÕES}

O comércio internacional está repleto de oportunidades e também de desafios. O aumento da concorrência (nacional e/ou internacional), a pressão pela redução de custos, a busca por novos fornecedores ou por novos clientes, a diminuição das barreiras ao comércio internacional, as crises econômicas são características do processo evolutivo do comércio internacional com o advento da globalização. Nesse contexto, o Brasil, que é conhecido como um país muito fechado para o comércio internacional, lançou em 2015 o Programa Brasileiro de OEA, desenvolvido com base no programa da aduana dos Estados Unidos, com o intuito de reduzir as barreiras alfandegárias e fomentar as operações de comércio exterior do país.

O programa OEA é o tema mais novo no contexto do comércio exterior e da logística internacional no Brasil. O governo espera que até 2019, 50\% (cinquenta por cento) de todas as declarações de importação e exportação registradas no Brasil sejam feitas por empresas certificadas no programa OEA. Diante desse contexto, o objetivo principal do estudo foi identificar os possíveis impactos na logística internacional para os agentes desta cadeia ao se certificarem no programa OEA Operador Econômico Autorizado, analisando as peculiaridades referentes ao processo de certificação do programa OEA e os benefícios logísticos que tal benefício pode proporcionar aos operadores certificados. Por meio de uma pesquisa documental e um estudo de caso foi possível chegar a algumas conclusões que serão apresentadas a seguir.

Atualmente no Brasil, apenas setenta e seis empresas estão habilitadas no programa brasileiro de OEA. Estas empresas atendem aos requisitos e às condições estabelecidas pela Receita Federal, entre eles: requisitos de admissibilidade, critérios de elegibilidade, critérios de segurança, critérios de conformidade e estão divididas em três categorias: OEA segurança, destinado a empresas exportadoras e prestadores de serviço da cadeia logística; OEA Conformidade Nível 1 e Nível 2, destinado a empresas importadoras e; OEA Pleno, destinado a empresas que realizam operações de importação e exportação.

A empresa analisada não apresentou nenhuma dificuldade para obtenção da certificação no programa OEA, entretanto, há de se ressaltar que a empresa já possuía o regime aduaneiro especial Linha Azul, antecessor ao programa OEA, portanto, entende-se que a habilitação de tais empresas será um processo natural, somente de adaptação e ampliação dos benefícios. Sendo assim, acredita-se que empresas de menor porte ou até mesmo empresas de grande porte que não eram habilitadas no Linha Azul encontrarão alguns desafios para a certificação tendo em vista à complexidade da 
legislação, quantidade de procedimentos e documentos necessários para certificação e morosidade no processo de avaliação por parte da Receita Federal.

Entre os benefícios atribuídos ao OEA, o mais notado na pesquisa foi a grande incidência do canal de parametrização verde, pelo qual a mercadoria é liberada automaticamente, sem a necessidade de conferência documental e/ou conferência física. Com o aumento da incidência do canal verde, o tempo de desembaraço é reduzido, como consequência o custo de armazenamento nas zonas alfandegadas é minimizado. Outros aspectos importantes para a logística estão relacionados à redução dos níveis de estoque, possibilidade de trabalho com a metodologia just in time, ganho de agilidade e eficiência em toda a cadeia da logística internacional. As empresas habilitadas passam a ter um canal direto de comunicação com a Receita Federal, com prioridade de respostas em consultas e análises.

$\mathrm{O}$ regime OEA é muito recente nas operações de comércio exterior, muitas empresas ainda estão se preparando para pleitear a habilitação e outras tantas talvez nem tenham tomado conhecimento sobre esse programa criado pelo governo brasileiro. Porém, as expectativas para que esse programa contribua para evolução do comércio exterior brasileiro são grandes, tanto para o aumento das exportações quanto para redução dos custos e da morosidade nos processos de importação.

Por fim, há de se ressaltar que a principal limitação do estudo está no método utilizado. $\mathrm{O}$ estudo de caso pode retratar uma realidade específica que nem sempre pode ser generalizada para as demais organizações, portanto, sugerem-se novos estudos sobre o tema buscando identificar a realidade das demais habilitadas no OEA brasileiro. Outra limitação da pesquisa é a falta de material e pesquisas sobre o assunto, ainda existem poucos pesquisadores e estudiosos dessa área no Brasil, sendo necessário para o desenvolvimento do artigo a frequente utilização de informações de sites especializados e de informações da Receita Federal.

\section{REFERÊNCIAS}

ANEFAC - Associação Nacional dos Executivos de Finanças, Administração e Contabilidade. OEA: Como as operações envolvendo comércio exterior serão beneficiadas e principais alterações tributárias. Disponível em: <http://www.anefac.com.br/>. Acesso em: 15 abr. 2016.

\section{ASSOSIAÇÃO BRASILEIRA DE} ESTUDOS ADUANEIROS. (2016). Programa OEA, OEA - Segurança e OEA

- Conformidade: Momento atual e perspectivas. Disponível em: <http://www.abead.org.br/noticias/programaoea-oea-seguranca-e-oea-conformidademomento-atual-e-perspectivas/>. Acesso em: 20 abr. 2016.

BRASIL. RECEITA FEDERAL. (2015). AEO - Authorized Economic Operator Programa Brasileiro de Operador Econômico Autorizado: Perguntas e 
Respostas. Disponível em:

$<$ http://idg.receita.fazenda.gov.br/orientacao/a duaneira/importacao-e-

exportacao/oea/arquivos-e-

imagens/arquivos/perguntas-respostas-

novo.pdf >. Acesso em: 15 abr. 2016.

BRASIL. RECEITA FEDERAL. (2015). INSTRUÇÃO NORMATIVA No 1.598, DE 9 DE DEZEMBRO DE 2015. Disponível em:

<http://www.jusbrasil.com.br/diarios/106138 061/dou-secao-1-11-12-2015-pg-33>. Acesso em: 16 abr. 2016.

BRASIL. RECEITA FEDERAL. (2016). Programa Brasileiro de Operador Econômico Autorizado. Disponível em: $<$ http://idg.receita.fazenda.gov.br/orientacao/a duaneira/importacao-e-exportacao/oea>. Acesso em: 15 abr. 2016.

\section{CHRISTOPHER, M. Logística e} gerenciamento da cadeia de suprimentos. (EZ2 translate, Trad., J. R. Hunter, Rev.). São Paulo: Cengage Learning, 2013.

\section{GIL, A.C.. Como elaborar projetos de} pesquisa. 4. ed. São Paulo: Atlas, 2002.

LOPES, J.M.C.; GAMA, M. Comércio exterior competitivo. 4. ed. São Paulo: Aduaneiras, 2013.

MACHADO, S.T.; SANTOS, R.C.; REIS, J.G.M.; OLIVEIRA, R.V.; DELIBERADOR, L.R.; CAVALCANTI, M. (2013). Estudo sobre a utilização de portos secos no Brasil e uma proposta de implementação desses no estado de Mato Grosso do Sul. RMS -

Revista Metropolitana de Sustentabilidade. Disponível em:

<http://www.revistaseletronicas.fmu.br/index. php/rms/article/view/204/pdf_1>. Acesso em: 05 jan. 2016.

PROCOMEX - Aliança Pró-Modernização Logística de Comércio Exterior. (2016). O que é um operador econômico autorizado? Disponível em:

<http://www.procomex.com.br/o-que-e-um- operador-economico-autorizado/ > . Acesso em: 15 abr. 2016.

ROCHA, P.C.A.. Logística e aduana. 4. ed. São Paulo: Aduaneiras, 2013.

SILVA, E.L.; MENEZES, E.M. Metodologia da pesquisa e elaboração de dissertação. 3 . ed. Florianópolis: Laboratório de Ensino a Distância da UFSC, 2001. Disponível em: <https://projetos.inf.ufsc.br/arquivos/Metodol ogia_de_pesquisa_e_elaboracao_de_teses_e_ dissertacoes_4ed.pdf $>$. Acesso em: 10 mar. 2015.

SOUZA, R.S. (2012). A logística

internacional e aviação civil: uma ênfase na logística reversa. Anais do II EnFAGEN Administração em Destaque. Uberlândia: II Encontro das Faculdades de Gestão e Negócios, 13-15 de junho de 2012.

SOUZA, R.S. Os portos secos como canais de comércio exterior. Dissertação: Mestrado Profissional em Administração, Fundação Cultural Dr. Pedro Leopoldo, Pedro Leopoldo, 2015. Disponível em: <http://www.fpl.edu.br/2013/media/pdfs/mest rado/dissertacoes_2015/dissertacao_reginaldo _da_silva_souza_2015.pdf $>$. Acesso em: 15 mar. 2016.

SOUZA, R.S.; LARA, J.E. (2015) Os portos secos como canais de comércio exterior. Anais II Cidesport, 2015. Disponível em: $<$ http://cidesport.com.br/sites/default/files/369 38.pdf $>$. Acesso em: 06 fev. 2016.

SOUZA, R.S.; SANTOS, D.R.; LUCIANO, C.P.R.; SILVA, F.M.C. Vantagens da utilização do regime aduaneiro especial Linha Azul - Despacho Aduaneiro. Anais XII Seget - Simpósio de Excelência, Gestão e Tecnologia, 28-30 de outubro de 2016. Disponível em: <http://www.aedb.br/seget/arquivos/artigos 15 /9122182.pdf>. Acesso em: 20 fev. 2016 